\title{
Effect of Low-Energy Inert-Gas Ion Bombardment of the Metal Surface on the Oxygen Adsorption and Oxidation
}

\author{
M. O. Vasylyev", S. I. Sidorenko ${ }^{\dagger}$, S. M. Voloshko ${ }^{\dagger}$, and T. Ishikawa \\ "G. V. Kurdyumov Institute for Metal Physics, N.A.S. of Ukraine, \\ 36 Academician Vernadsky Blvd., \\ UA-03680 Kyiv-142, Ukraine \\ ${ }^{\dagger}$ National Technical University of Ukraine 'Kyiv Polytechnic Institute', \\ 37 Peremogy Ave., \\ UA-03056 Kyiv-56, Ukraine \\ ${ }^{\ddagger}$ RIKEN Spring-8 Centre, \\ 1-1-1 Kouto, \\ Sayo-cho, Sayo-gun, Hyogo 679-5198, Japan
}

It is well known that the metal-surface properties vary because of the ion sputtering of surface layers in a vacuum. This review contains results of the studies of kinetics change of both oxygen adsorption and oxidation on the surface of transition metals and alloys in a vacuum during the lowenergy ( $<10 \mathrm{keV}) \mathrm{Ar}^{+}$ions' bombardment. Particularly, the results of the systematic studies of a surface of the $\mathrm{Cu}, \mathrm{Ni}, \mathrm{Fe}$, Co single crystals, and $\mathrm{Fe}-\mathrm{Ni}$ alloy are presented. The important role of such parameters as a dose of the ion bombarding, ion energy and sample temperature in the chemical activity of a surface is noted. As argued, mechanism of interaction in surface-gas system is substantially controlled by the optimal ratio between the energy and the primary ion current density as well as the sputtering rate of natural oxide on the target surface.

Добре відомо, що властивості поверхні металу змінюються в результаті йонного розпорошення поверхневих шарів у вакуумі. Даний огляд містить результати досліджень зміни кінетики адсорбції кисню й окиснення на поверхні перехідних металів і стопів у вакуумі при бомбардуванні йонами $\mathrm{Ar}^{+}$низької енергії (< 10 кеВ). Зокрема, наведено результати систематичних досліджень поверхні монокристалів $\mathrm{Cu}, \mathrm{Ni}, \mathrm{Fe}$, Co та стопу $\mathrm{Fe}-\mathrm{Ni}$. Зазначено важливу роль таких параметрів як доза бомбардування, енергія йонів і температура зразка у зміні хемічної активности поверхні. Наведено докази того, що механізм взаємодії в системі газ-поверхня істотно контролюється оптимальним співвідношенням між енергією та густиною первинного йонного струму, а також швидкістю розпорошення природного оксиду на поверхні мішені. 
Хорошо известно, что свойства поверхности металла изменяются в результате ионного распыления поверхностных слоёв в вакууме. Данный обзор содержит результаты исследований изменения кинетики адсорбции кислорода и окисления на поверхности переходных металлов и сплавов в вакууме при бомбардировке ионами $\mathrm{Ar}^{+}$низкой энергии $(<10$ кэВ). В частности, приведены результаты систематических исследований поверхности монокристаллов $\mathrm{Cu}, \mathrm{Ni}, \mathrm{Fe}$, Co и сплава Fe-Ni. Отмечается важная роль таких параметров как доза бомбардировки, энергия ионов и температура образца в изменении химической активности поверхности. Приведены доказательства того, что механизм взаимодействия в системе газ-поверхность существенно контролируется оптимальным соотношением между энергией и плотностью первичного ионного тока, а также скоростью распыления природного оксида на поверхности мишени.

Keywords: ion bombardment, oxygen adsorption, oxidation, metal and alloy surfaces, radiation defects.

Ключові слова: йонне бомбардування, адсорбція кисню, окиснення, поверхні металу та стопу, радіяційні дефекти.

Ключевые слова: ионная бомбардировка, адсорбция кислорода, окисление, поверхности металла и сплава, радиационные дефекты.

(Received June 6, 2016)

\section{INTRODUCTION}

Nowadays, low-energy $(<10 \mathrm{keV})$ inert gas ion bombardment of the material surface is widely used in various fields of the science and technology. As an example, we note ion beam assisted physical or chemical deposition coatings and thin films for improving both adhesion behaviour and physicochemical properties [1-4]. Low-energy inert-gas ion beam is often used in the various methods of surface analysis of semiconductors and metals, for example, in secondary ion mass spectrometry (SIMS) [5, 6] and transmission electron microscopy (TEM) [7, 8].

It is well known that the metal-surface properties can be altered by low-energy ion bombardment because of the sputtering of surface atomic layers that occurs in the vacuum chamber. It is generally believed that the enhanced adhesion phenomena of thin films on the metal surfaces by means of ion sputtering is related to removing from the substrate some natural oxides and different kind of impurities. However, the surface chemical activity can be also altered by inert gas low-energy ion sputtering. For example, early experimental work showed that catalysts were almost one order of magnitude more efficient than unirradiated ones [9]. Most naturally, these 
pioneering contributions were interpreted qualitative in terms of a picture, in which surface defects resulting from ion bombardment were considered as the structural descriptions of the rather elusive 'active centres'. It was first observed visible by the naked eye that after certain doses of bombardment by $\mathrm{Ar}^{+}$or $\mathrm{He}^{+}$ions $(<10 \mathrm{keV})$ the surface of $\mathrm{U}, \mathrm{Fe}, \mathrm{Al}$, and $\mathrm{Cu}$ become passivity with respect to oxidation under atmospheric conditions [10-12].

Closer examination of the influence of inert gas ion bombardment with incident ion energies of order of $1 \mathrm{keV}$ on the surface chemical activity has been performed by the examples of gas-surface interaction in vacuum conditions, in a particular of the kinetics of oxygen interaction with surface of $\mathrm{Cu}, \mathrm{Ni}$, and $\mathrm{Fe}$ using variety of techniques [13-18]. It was reported that gas-surface interactions and surface reactivity is strongly controlled by the optimal relation between the energy and the density of the primary ion current as well as the sputtering rate of natural oxide and pure metal.

Since the passivation effects at atmospheric conditions after ion bombardment of metal surfaces are currently unknown, we review here only the main results, which were obtained during observations these effects in a vacuum for several pure metals and alloys.

\section{PURE METALS}

The first attempt to study the effect of initial ion bombardment on the metal oxidation in vacuum was performed by Cherepin et al. in 1962 [13]. They used the method of SIMS for the study of various surface phenomena such as the oxygen adsorption on the metal surface. The samples used in this work consisted of pure polycrystalline iron $\left(2 \cdot 10^{-3}\right.$ at. $\%$ of impurities $)$. The surface studied was polished mechanically, diamond finished and rinsed in special solutions. After this treatment, the samples were kept in oxygen at atmospheric pressure in order to obtain an oxide layer of a definite thickness. Formation of the oxide layer $(\approx 8 \mathrm{~nm})$ was controlled by Auger electron spectroscopy (AES). Six samples were placed in the vacuum chamber of the SIMS apparatus [19] and then bombarded with $8 \mathrm{keV} \mathrm{Ar}{ }^{+}$ions beam (current density of $1.5 \cdot 10^{-3} \mathrm{~A} \cdot \mathrm{cm}^{-2}$ ). The time of bombardment was varied so that the doses of irradiation ranged from $10^{-16}$ to $10^{-19}$ ion $\cdot \mathrm{cm}^{-2}$. The partial oxygen pressure during bombardment was not higher than $2 \cdot 10^{-8}$ Torr. Immediately after bombardment oxygen at pressures of $10^{-7}, 10^{-6}$ and $10^{-5}$ Torr was led into the vacuum chamber. These pressures were maintained for a definite time to obtain oxygen doses of $3 \cdot 10^{2}, 3 \cdot 10^{3}$ and $3 \cdot 10^{4}$ $\mathrm{L}$, respectively. Then, the chamber was pumped down again. The secondary ion current of ${ }^{56} \mathrm{Fe}^{+}$and ${ }^{16} \mathrm{O}^{-}$isotopes were measured during bombardment with the $\mathrm{Ar}^{+}$ion beam having the above- 
mentioned parameters. It was found the exponential decrease of these secondary ion currents during sputtering by inert gas ions due to the removal of an oxide layer from the surface. The final level of the secondary current may be considered as corresponding to dynamic equilibrium between the rate of the primary ions arrival (and hence sputtering rate of the iron ions) and the rate of the oxygen adsorption from the residual gas in the vacuum chamber.

Analysis of the kinetic curves $I^{+}$for ${ }^{56} \mathrm{Fe}^{+}$and ${ }^{16} \mathrm{O}^{-}$ions showed that the initial ion treatment does not exclude oxidation of iron surface. However, variation of the initial bombardment and subsequent oxidation doses leads to appreciable change in the height of the initial spike in the curves $I^{+}(\tau)$. The results of the quantitative estimate these effects are shown in Fig. 1. Here, $\Delta I^{+}=I_{1}^{+}-I_{\mathrm{O}}^{+}$values are plotted as function of the bombardment doses $D$ where $I^{+}$is the height of the initial current peak (corresponding the initial oxide layer); $I_{\mathrm{O}}{ }^{+}$is the current corresponding to dynamic equilibrium (approximately it corresponds to the surface oxygen concentrations less than one monolayer). It should be mentioned that the value of $I_{\mathrm{O}}{ }^{+}$does not depend on $D$. Hence, initial bombardment does not influence the ion emission after the removal of the oxide layer of the surface. As follows from Fig. 1, the quantity $\Delta I^{+}$depends on the exposure in oxygen and on the dose of ion bombardment. The minima in the $\Delta I^{+}(D)$ curves correspond to doses of $2 \cdot 10^{17}-3 \cdot 10^{17}$

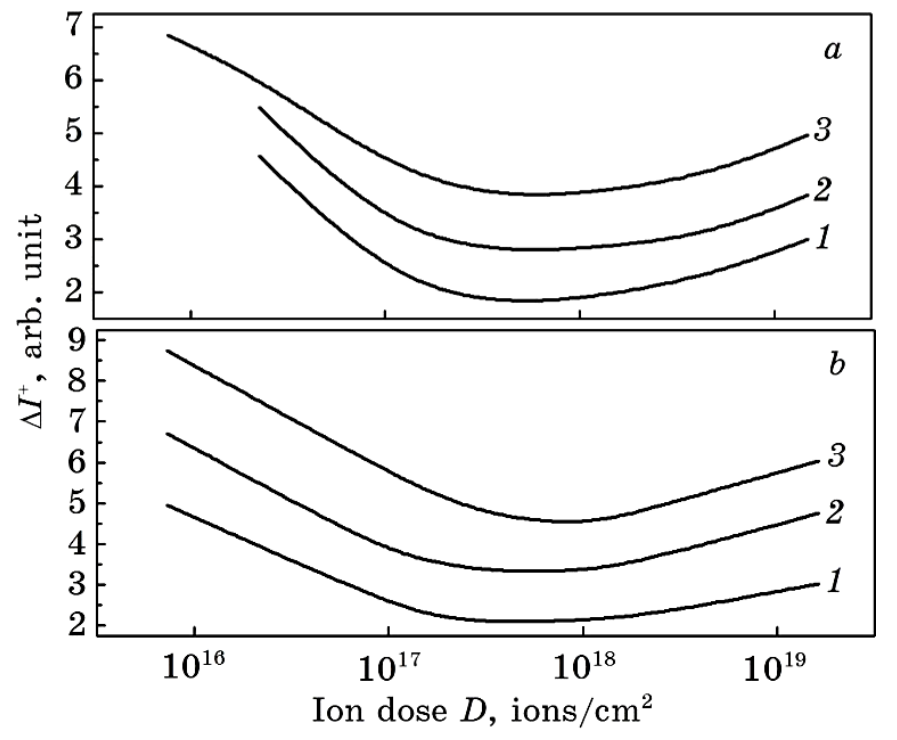

Fig. 1. ${ }^{56} \mathrm{Fe}^{+}(a)$ and ${ }^{16} \mathrm{O}^{+}(b)$ ion current from iron sample as a function of $\mathrm{Ar}^{+}$ion bombardment dose $D\left(1 \mathrm{keV}, 1.2 \mathrm{~mA} \cdot \mathrm{cm}^{-2}\right): 1-300 \mathrm{~L} ; 2-3000 \mathrm{~L}$; $3-30300 \mathrm{~L}$. 
ion $\cdot \mathrm{cm}^{-2}$ Bombardment with such doses makes the surface free of the primary oxide layer (formed under atmospheric conditions). Hence, the quoted minima refer to the secondary ion emission from the oxide formed on the metal exposed to oxygen.

The change in the oxidation rate caused by the ion treatment was explained as follows. When the irradiation dose is insufficient for a complete removal of the primary oxide, there remain oxide layers whose further growth is hindered by a possible formation of a barrier produced by argon atoms implanted into the oxide layer. This causes decrease in the diffusion rate of the metal and oxygen atoms. Hence, this effect is controlled by the optimal relation between the energy and the density of the primary ion current as well as by the sputtering rate of primary oxide and pure metal. The increase in the oxidation rate at high doses may be as results a large number of defects and the relief created on the metal surfaces.

Miranda et al. [14] first used AES in order to study the influence of $\mathrm{Ar}^{+}$ion bombardment $\mathrm{Ni}(001)$ on the subsequent incorporation of the oxygen in the high vacuum. Usual cleaning involved heavy ion bombardment followed by annealing at $1000 \mathrm{~K}$ and a final treatment with oxygen at a pressure of $1 \cdot 10^{-8}$ Torr during $10 \mathrm{~min}$ with the sample at $700 \mathrm{~K}$. After a final flash, no traces of oxygen were detectable. The base pressure was usually better than $2 \cdot 10^{-10}$ Torr. These authors first used low energy $\mathrm{Ar}^{+}$ion bombardment at 500 $\mathrm{eV}$. The ion dose was corresponded to one $\mathrm{Ar}^{+}$ion per Ni surface atom. Oxygen was introduced through a leak valve. All the bombardment and oxygen exposures were carried out at room temperature.

The effects of the ion irradiation on oxidation are represented in Fig. 2 for $P_{\mathrm{O}_{2}}=1 \cdot 10^{-7}$ Torr and for ion dose $\theta^{+}$from 0 to $20\left(\theta^{+}=1\right.$ means $1 \mathrm{Ar}^{+}$per surface atom, and $r=\mathrm{O}(512 \mathrm{eV}) / \mathrm{Ni}(848 \mathrm{eV})$ is the ratio of $\mathrm{O}$ and $\mathrm{Ni}$ Auger peaks). It was pointed that all the curves for different $\theta^{+}$reach finally a saturation value $\left(r_{\infty}=1.85\right)$. This value is practically equal to $r=1.9$ for vacuum-cleaved NiO. On the other hand, the times required for saturation depend strongly on irradiation dose as seen in Fig. 2. On this basis, it was concluded that $\mathrm{Ni}$ samples were completely oxidized down to the escape length of the Auger electrons. In addition, it is clear that irradiation enhances oxygen incorporation into the sample.

Miranda et al. [14] suggested that sputtering yields are of the order of unity for their bombardment parameters. Consequently, one would expect saturation of the number of the surface sites induced by radiation damage precisely at that range of doses. Then, the influence of ion irradiation up to doses of the order of $\theta^{+}=1$ seems to be connected with an enhancement of the nucleation sites. It was also tentatively proposed that the slower increase the maximal slope on each curve in Fig. 2 is due to increasing sub-surface 


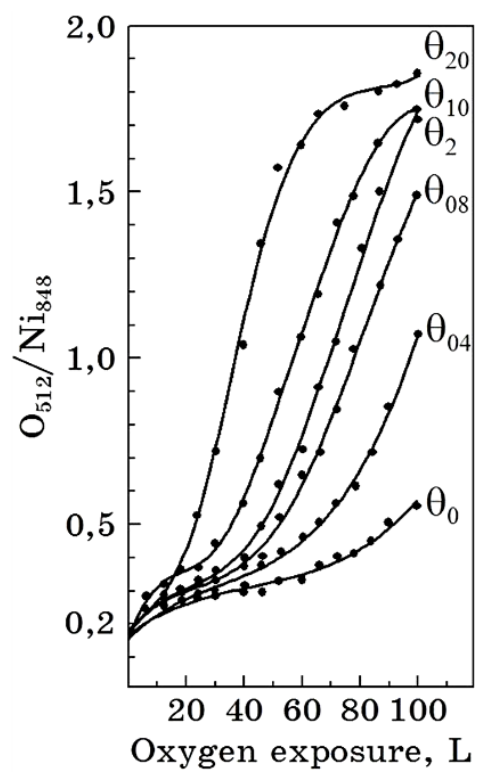

Fig. 2. The ratio of oxygen and nickel Auger peaks $\left(r=\mathrm{O}_{512} / \mathrm{Ni}_{848}\right)$ as a function of oxygen exposure at $p_{\mathrm{O}_{2}}=1.0 \cdot 10^{-7}$ Torr.

damage. Indeed, electron microscope observations have shown that ion bombardment damage extends down to several layers (perhaps 10-20) of the material (in the form primarily of point defect clusters and dislocation half-loops). After this, damage also becomes saturated because of the continuous receding of the surface due to sputtering. As the sputtering yield is of the order of unity the ion doses required for saturation, $\theta^{+}$, will be of the order of the depth of damaged layers $\left(\theta^{+}=10-20\right.$ perhaps $)$. It was not excluded that all these above surface defects increase the rate of oxidation by facilitating the diffusion of the chemical species involved in the corresponding tarnish reaction or by acting as sinks for the extra vacancies involved in the oxidation process. However, one can wonder if defects are necessary for oxide nucleation.

In the next work, Miranda et al. [15] studied the effect of $\mathrm{Ar}^{+}$ bombardment on the oxidation of $\mathrm{Fe}(110)$ by oxygen and water in vacuum. They used for this aim AES and LEED. Surface damage was created by $\mathrm{Ar}^{+}$bombardment $(500 \mathrm{eV})$ on a clean and initially well-annealed $1000 \mathrm{~K}$ surface, which exhibited a sharp LEED pattern. Ion dose was given in units of $\theta^{+}$, where $\theta^{+}=1$ means an ion dose of the one argon atom, on the average, per surface iron atom. The oxygen concentration at the surface was monitored by measuring the ratio, $r$, of Auger peak amplitudes of oxygen and iron signals.

Figure 3 displays the evolution $r$ as a function of oxygen expo- 


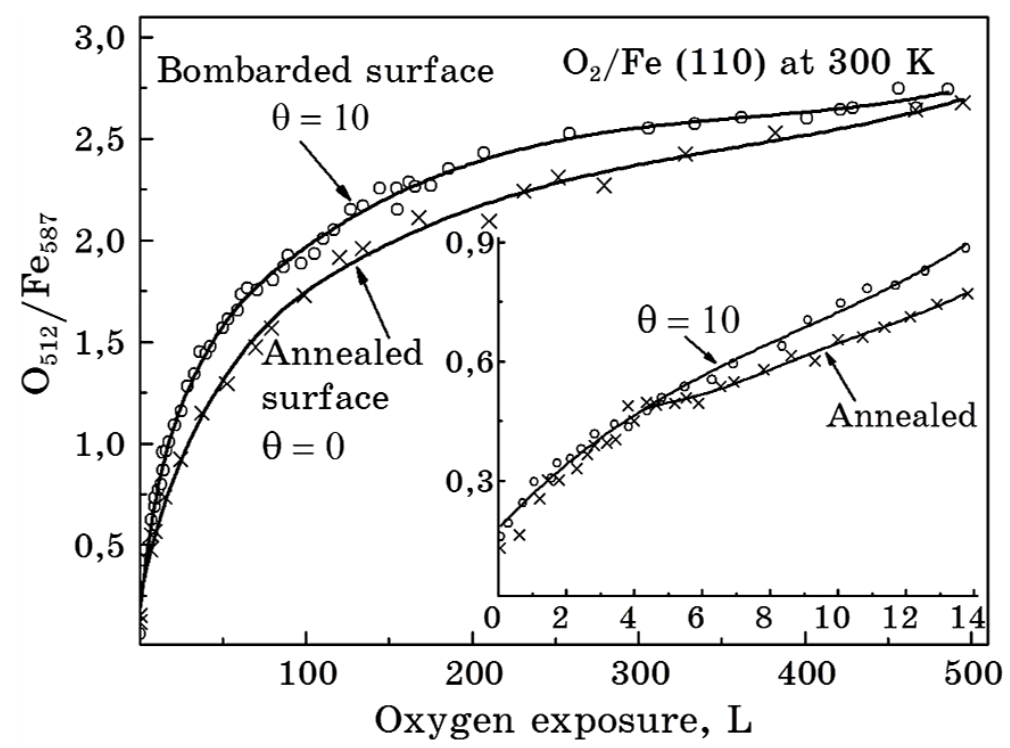

Fig. 3. Evolution of the $\mathrm{O}_{512} / \mathrm{Fe}_{587}$ Auger peak ratio as a function of the oxygen exposure for a non-bombarded and Ar bombarded surface. The insert shows in detail the low exposure region.

sure for an annealed and for a bombarded surface $\left(\theta^{+}=10\right)$. For exposures above $\cong 450 \mathrm{~L}$, both curves overlap. After an exposure of $3 \cdot 10^{3} \mathrm{~L}$, it was obtained $r_{\mathrm{O}_{2}}=3.0$, which is close to the value of 3.3 for the $\mathrm{FeO}$ sample. The oxygen uptake curves for the annealed and Ar bombarded surfaces coincide up to $5 \mathrm{~L}$ and separate above this value. The oxygen coverage at the plateau is 0.4 monolayers.

The data in Fig. 3 indicate that the sticking coefficient in the chemisorption stage is not affected by bombardment but the rate of formation of surface oxide is enhanced by surface defects created by ion bombardment. Thus, the authors [15] observed that one could accelerate the growth of surface oxide via increasing the ion dose. The nucleation rate of the surface oxide must be dependent on the density of the nucleation centres at the surface. An increase in the ion bombardment dose from $\theta^{+}=1$ to $\theta^{+}=10$ resulted in an increase in the surface density of the nucleation centres for oxide growth that, in turn, leads to an enhancement of the surface oxidation rate. It was suggested that ion bombardment may create monoatomic steps of (110) symmetry, which could be the nucleation centres for the oxide formation. This means that the average size of an oxide island at the surface reaches some maximum value that could be related to the number of step atoms at the surface induced by the impact of Ar ions.

The authors of Ref. [16] have also performed the same type of 
experiments with water vapour, which was introduced to vacuum chamber. It was observed that $\mathrm{Ar}^{+}$bombardment inhibits the passivation effect caused by the adsorbed oxygen layer after water exposure on the annealed surface, by allowing oxygen atoms to penetrate into the crystal.

Chenakin [17] performed the first systematic study of the effect of inert-gas ion bombardment on the oxidation of the different metal surfaces. He gives the results of a study of the kinetics of oxygen chemisorption on $\mathrm{Cu}, \mathrm{Ni}, \mathrm{Fe}$ and Co surfaces after $\mathrm{Ar}^{+}$bombardment as a function of such parameters as ion dose and energy and the sample temperature. The investigated metals were polycrystals with impurity content less than $5 \cdot 10^{-3}$ at. $\%$. The main method of investigation was AES. The final preparation of the specimen surface in the chamber of Auger spectrometer consisted of several cycles of bombardment by $\mathrm{Ar}^{+}$with energy $600 \mathrm{eV}$ and annealing at $600^{\circ} \mathrm{C}$. After cleaning, the metal surfaces were successively bombardment by $\mathrm{Ar}^{+}$ions either in the dose range $10^{14}-10^{18}$ ion $\cdot \mathrm{cm}^{-2}$ $\left(j=7.5 \mu \mathrm{A} \cdot \mathrm{cm}^{-2}\right)$ at energy of $5 \mathrm{keV}$ or in the energy range $1-8 \mathrm{keV}$ with dose $1 \cdot 10^{14}$ and $1 \cdot 10^{18} \mathrm{ion} \cdot \mathrm{cm}^{-2}$. Then the set of samples was exposed to oxygen of high purity under a partial pressure of $1.33 \cdot 10^{-5} \mathrm{~Pa}(0-700 \mathrm{~L})$ and $1.33 \cdot 10^{-4} \mathrm{~Pa}(700-5000 \mathrm{~L})$. After each exposure, the oxygen was pumped out and Auger spectra were recorder. In order to estimate the change in the adsorption capacity of the metal surface because of the ion bombardment or the surface passivation effect, the following quantity was introduced:

$$
\gamma=\left[\left\{\left(h_{\mathrm{O}} / h_{M e}\right)_{\mathrm{ref}}-\left(h_{\mathrm{O}} / h_{M e}\right)_{\mathrm{bomb}}\right\} /\left(h_{\mathrm{O}} / h_{M e}\right)_{\mathrm{ref}}\right] \cdot 100 \%
$$

where $h_{\mathrm{O}} / h_{M e}$ is the ratio of the Auger peaks of oxygen (KLL) and metal (LMM); 'ref' and 'bomb' correspond to control (unirradiated) and bombarded samples, respectively. Then, positive values of $\gamma$ correspond to the suppression of $\mathrm{O}_{2}$ chemisorption on a bombarded metal as compared to control one, while negative values of $\gamma$ correspond to chemisorption enhancement. At high $\mathrm{O}_{2}$ exposures, $\gamma$ value characterizes the resistance to oxidation for the samples after ion bombardment.

Figure 4 shows the dependence of $\gamma$ on the $\mathrm{O}_{2}$ exposure for $\mathrm{Fe}$, $\mathrm{Co}, \mathrm{Ni}$, and $\mathrm{Cu}$ after ion bombardment with $D=10^{18}$ ion $\cdot \mathrm{cm}^{-2}$. It may be seen that $\gamma$ varies as the chemisorption proceeds (and varies differently for different elements). For example, the initially strong effect of chemisorption retardation on Fe decreases monotonously with the exposure growth, while for $\mathrm{Ni}$ the opposite picture is observed. In the range of $\mathrm{O}_{2}$ exposures up to $5000 \mathrm{~L}$, the formation of oxides on $\mathrm{Fe}$, $\mathrm{Ni}$ and $\mathrm{Co}$ is possible as may be judged from the behaviour of the low- and high-energy Auger peaks of the metal. 


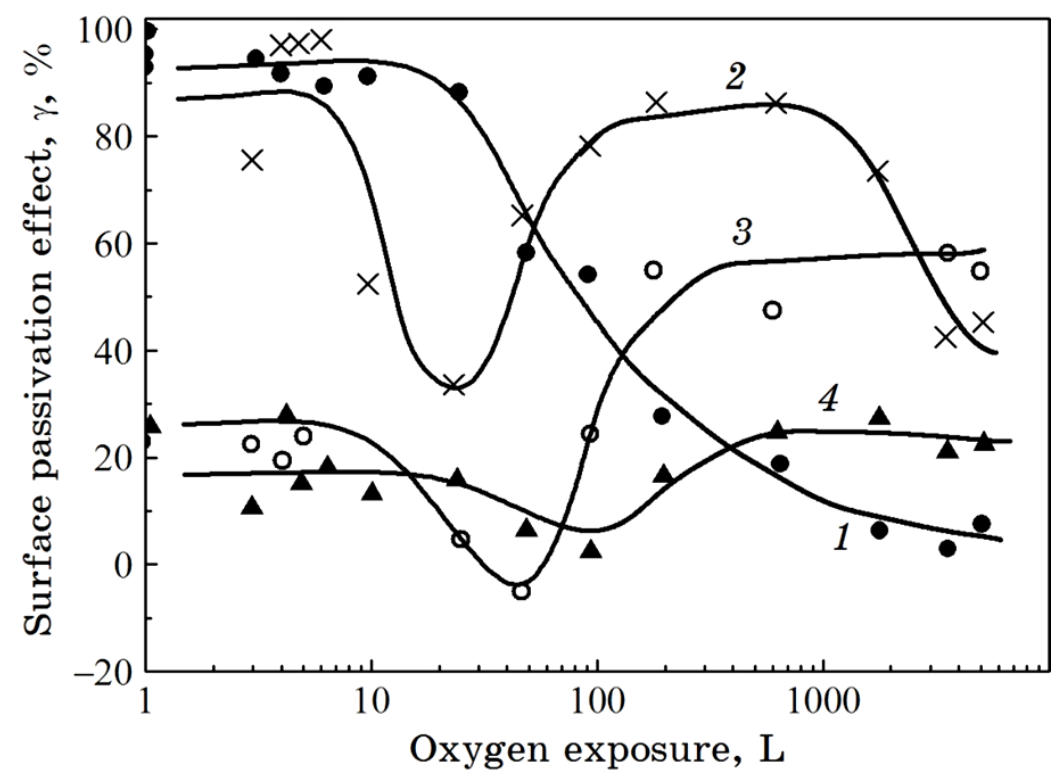

Fig. 4. Magnitude of the surface passivation effect for metals irradiated by $\mathrm{Ar}^{+}$ions at a dose of $10^{18} \mathrm{~cm}^{-2}$ as a function of $\mathrm{O}_{2}$ exposure: $\mathrm{Fe}-1, \mathrm{Co}-2$, $\mathrm{Ni}-3, \mathrm{Cu}-4$.

Analysis of the Auger peak shapes for $\mathrm{Fe}$ and $\mathrm{Ni}$ as a function of $\mathrm{O}_{2}$ for the reference (control) sample and for the sample irradiated with the dose $1 \cdot 10^{18}$ ion $\cdot \mathrm{cm}^{-2}$ has led to the following conclusions. A marked variation of $\mathrm{Fe}_{\mathrm{MVV}}$ Auger peak shape (47 eV), indicating oxide formation (the appearance of a split peak with energies 45 and $51 \mathrm{eV}$ ), was observed after the dose $200 \mathrm{~L}$ for the reference sample and after $100 \mathrm{~L}$ for the implanted one. For $\mathrm{Ni}$, the change in the LMM peak shape $(848 \mathrm{eV})$ for the reference and irradiated samples occurred at exposures above $700 \mathrm{~L}$ and $3000 \mathrm{~L}$, respectively. The appearance of oxide considerably stimulates chemisorption; therefore, the difference in the $\mathrm{O}_{2}$ chemisorption rates in the control and the irradiated samples as the exposure increases will decrease for $\mathrm{Fe}$ and will increase for $\mathrm{Ni}$. On $\mathrm{Cu}$, the oxide is not formed all the way up to $5000 \mathrm{~L}$; therefore, $\gamma$ depends weakly on the $\mathrm{O}_{2}$ exposure. Co behaves in a way intermediate between the behaviour of $\mathrm{Fe}$ and $\mathrm{Ni}$.

Figure 5 gives the values of $\gamma$ for $\mathrm{Fe}, \mathrm{Co}, \mathrm{Ni}$, and $\mathrm{Cu}$ for exposures of 3 and $5000 \mathrm{~L}$ after ion bombardment with $D=1 \cdot 10^{15}$, $1 \cdot 10^{16}, 1 \cdot 10^{18}$ ion $\cdot \mathrm{cm}^{-2}$. As is evident from Fig. 5, $a$, the magnitude of $\gamma(3 \mathrm{~L})$, which is determined by the difference between the initial chemisorption rates on the control and implanted samples, depends on the nature of the metal and the ion dose, and the dependence of $\gamma(3 \mathrm{~L})$ on the ion dose is different for different metals. In order to 


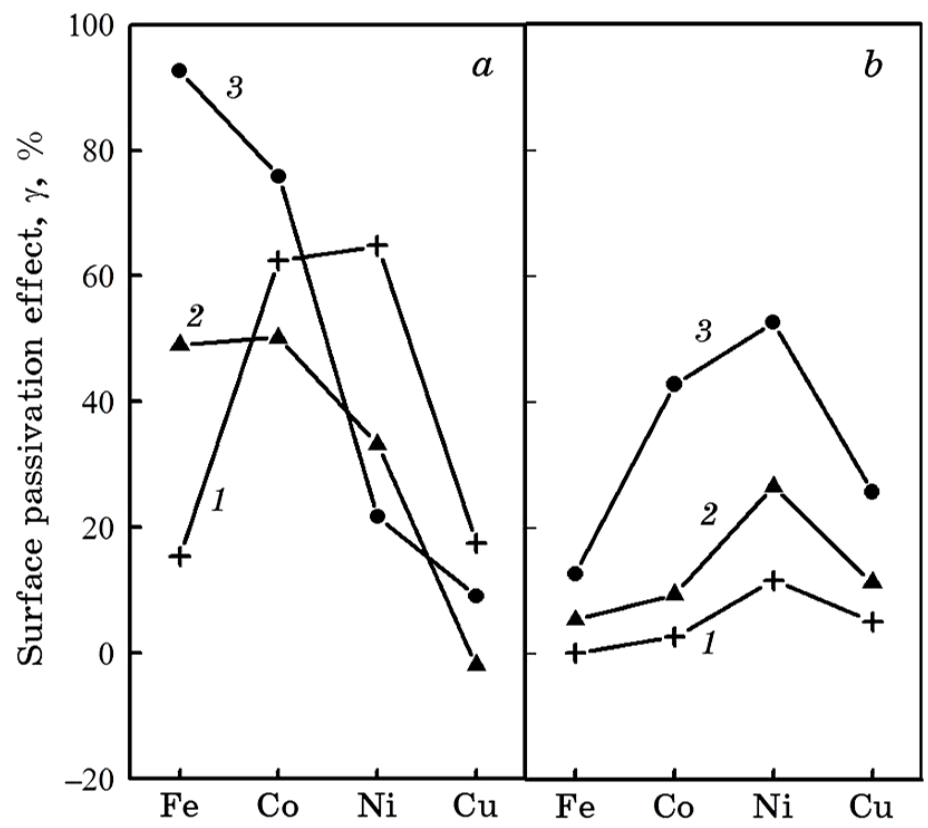

Fig. 5. Magnitude of the passivation effect for $\mathrm{O}_{2}$ exposures of $3 \mathrm{~L}(a)$ and $500 \mathrm{~L}(b)$ as a function of the nature of the metals implanted with $\mathrm{Ar}^{+}$ions with doses of $10^{15}(1), 10^{16}(2)$, and $10^{18}(3)$.

explain the results obtained, the model was adopted based on the following two main assumptions: (1) point defects (such as vacancies or dislocation emergence points) and clusters of point defects created at the surface by ion bombardment serve adsorption centres and thus enhance the adsorption rate; (2) implanted Ar ions block up the adsorption centres by reducing the chemisorption energy on atoms nearest to defects so that the adsorption rate becomes lower. The competitive effect of these two factors on the adsorption process should determine the kinetic character of interaction between oxygen and an irradiated metal.

The chemisorption rate is known to be described by

$$
V_{\text {ads }}=\left\{p /(2 \pi m k T)^{1 / 2}\right\} \sigma(\theta) f(\theta) \exp \left[-E_{\mathrm{A}}(\theta) /(R T)\right],
$$

where $p$ is the gas pressure, $m$ is the gas molecular mass, $T$ is the temperature, $\sigma(\theta)$ is the sticking coefficient, $f(\theta)$ is the probability that the molecule will hit the unoccupied site, $E_{\mathrm{A}}$ is the adsorption activation energy, $\theta$ is the coverage, $R$ is the gas constant, $k$ is the Boltzmann constant. The sticking coefficient of oxygen is known to be enhanced due to damage produced in a metal by in bombardment $[20,21]$. Defect sites at the surface can (in addition) reduce the ac- 
tivation energy $E_{\mathrm{A}}$ of the dissociative adsorption [6, 22]. Hence, radiation defects produced by ion bombardment must modify the absorbability of the metal surface according to Eq. (2). As a result, the initial rate of adsorption, $V_{\text {ads }}$, and the amount of adsorbed at low exposures (less than $50 \mathrm{~L}$ ) should become higher with the growth in the surface defect density, which, in its turn, should increase with irradiation dose. This agrees with the experimentally observed growth of the ratio $h_{\mathrm{O}} / h_{\mathrm{Cu}}$ in the dose range $10^{14}-10^{18}$ ion. $\mathrm{cm}^{-2}$ at exposures up to $50 \mathrm{~L}$ (Fig. 6).

With an increase in the exposure, oxygen adsorption will occur at sites with required higher activation energy and which ensure lower chemisorption energy. According to theoretical evaluations [23], the chemisorption energy of atoms nearest to a defect is reduced by 10$15 \%$. Hence, for the samples with a high density of defects (irradiated with a larger dose), the sticking coefficient will drop abruptly, and the adsorption will be reduced (Fig. 6,200 L). The fact that the chemisorption energy is decreased on atoms closest to the defect may be treated as equivalent to the blocking action of implanted argon assumed in model. Due to this factor, the amount of oxygen chemisorbed at large exposures may become smaller as the ion dose increases (Fig. 6, 5000 L). The kinetics of sputtering of oxygen,

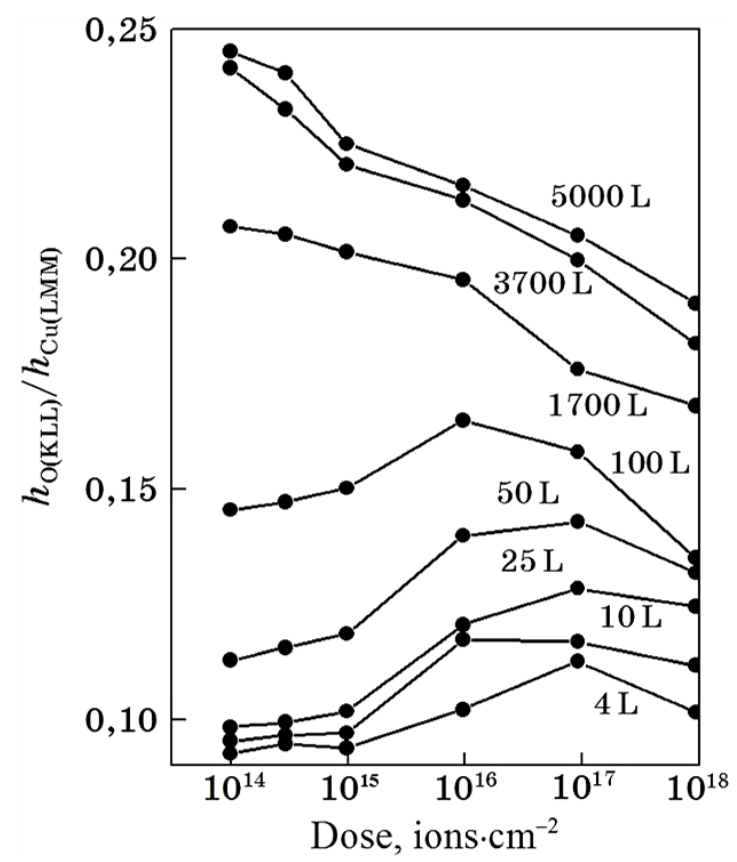

Fig. 6. Intensity ratio, $h_{\mathrm{O}(\mathrm{KLL})} / h_{\mathrm{Cu}(\mathrm{LMM})}$, vs. dose of preceding $\mathrm{Ar}^{+}$bombardment for various oxygen exposures. 
which was chemisorbed on $\mathrm{Cu}$ at $5000 \mathrm{~L}$ (Fig. 7) supports the idea that the binding energy of adsorbed atoms decreases with an increase in ion dose.

In order to explain the effect of passivation, it was assumed that retardation of $\mathrm{O}_{2}$ chemisorption on irradiated metals as compared to unirradiated ones might be associated with the blocking of the adsorption centres by argon atoms. The concentration of the implanted argon atoms (neglecting their desorption) in the surface layer of $\mathrm{Fe}, \mathrm{Co}, \mathrm{Ni}$, and $\mathrm{Cu}$ was calculated for the range of ion doses under study. The following relation has been used [23]:

$$
C_{\mathrm{Ar}}(\mathrm{O}, t)=\left[j_{\mathrm{o}} /\left(2 e V_{s}\right)\right]\left\{\operatorname{erf}\left[t V_{s}-\left(R_{p} / 2\right) \Delta R_{p}\right]+\operatorname{erf}\left[R_{p} /\left(2 \Delta R_{p}\right)\right]\right\},
$$

where $j_{\mathrm{O}}$ is the $\mathrm{Ar}^{+}$current density, $V_{s}$ is the sputtering rate, $t$ is the bombardment duration, $R_{p}$ is the ion-projected range, $\Delta R_{p}$ is the straggling, and $e$ is the electron charge. The $R_{p}$ value may be found as follows [24]:

$$
R_{p}=C_{1} M_{2}\left\{\left[\left(Z_{1}{ }^{2 / 3}+Z_{2}{ }^{2 / 3}\right) /\left(Z_{1} Z_{2}\right)\right] E\right\}^{2 / 3} .
$$

Here, $C_{1}$ is a function of $M_{2} / M_{1}, Z_{1}$ and $Z_{2}$ are the atomic numbers of ion and target atoms, respectively, $E$ is the ion energy, and $M_{2}$ is

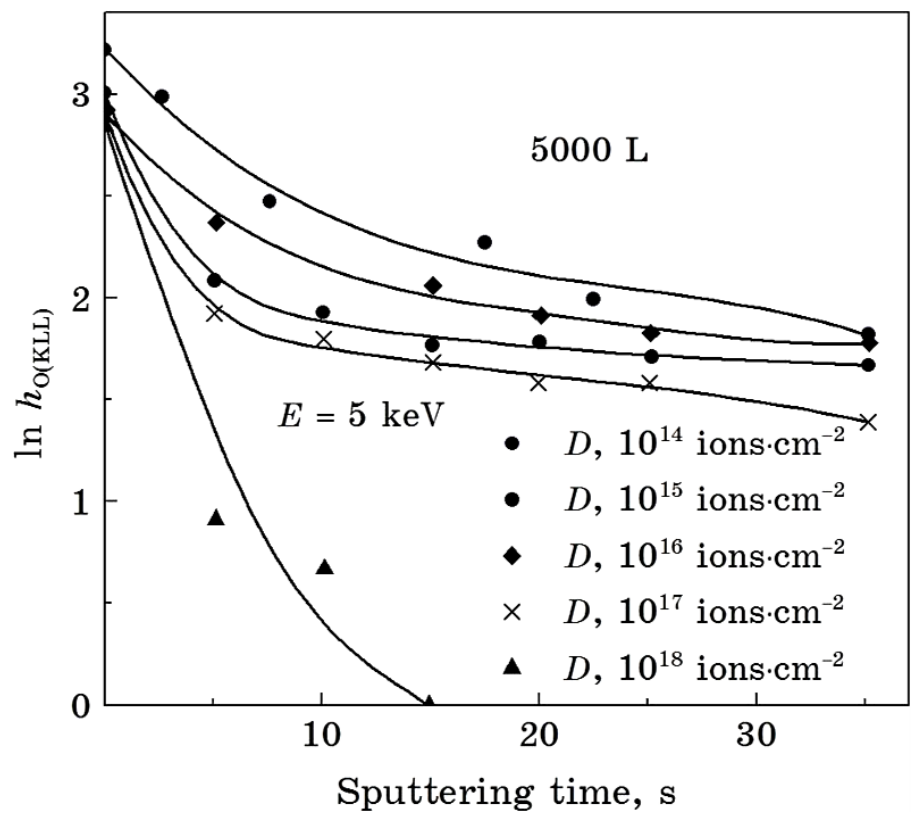

Fig. 7. Sputtering kinetics of oxygen chemisorbed on $\mathrm{Cu}$ at $5000 \mathrm{~L}$ after different irradiation doses. 
the target mass.

Figure 8 gives the value of $C_{\mathrm{Ar}}(\mathrm{O}, t)$ and measures values of $\gamma=$ $=h_{\mathrm{Ar}} / h_{M e(\mathrm{LMM})}$. It may be seen from a comparison of Fig. 8 that for every dose there is a good qualitative correlation between $\gamma$ and $C_{\mathrm{Ar}}(\mathrm{O}, t)$ for the series of metals. At the same time, the dependences of $\gamma$ and $C_{\mathrm{Ar}}(\mathrm{O}, t)$ on the ion dose $D$ do not correlate between themselves for a given metal (except Fe). This may be due to the fact that the adsorption process is strongly affected by radiation defects whose density, distribution and type are not really related to the ion dose. As may be seen from Fig. 8, the character of $\gamma$ dependence on the metal nature and the ion dose $D$ varies with an increase in exposure. At $5000 \mathrm{~L}$, the degree of reduction in chemisorption becomes higher as the dose increases for all the metals. Under these circumstances, the influence of radiation defects seems to be already weakened and the concentration of implanted argon atoms plays the main role. The investigations of the oxygen chemisorption kinetics on implanted $\mathrm{Cu}$ at different temperatures [17] allow obtaining the Arrhenius plot for the initial chemisorption rate and for the chemisorption rate at different oxygen exposures.

It is known that $\mathrm{O}_{2}$ adsorption on unirradiated $\mathrm{Cu}$ is an activated

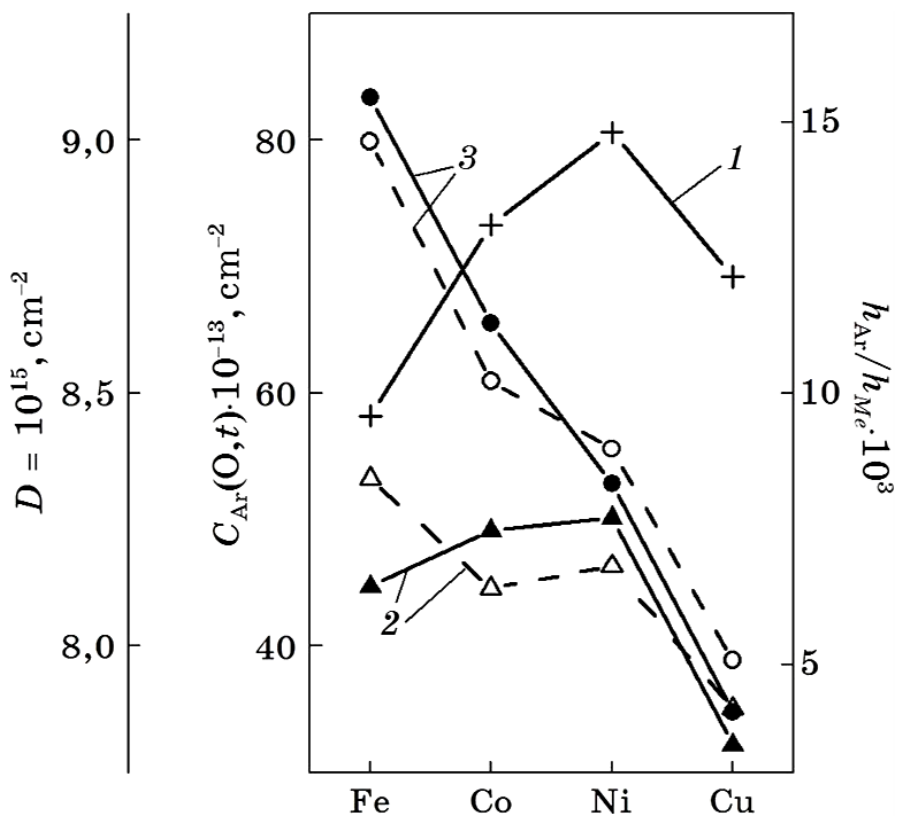

Fig. 8. Calculated concentration of $\mathrm{Ar}$ atoms in the surface layer $C_{\mathrm{Ar}}(\mathrm{O}, t)$ (solid line) and the ratio of the amplitudes for the Auger peak Ar LMM and the LMM peak of the metal (dashed line) as a function of the nature of the metal irradiated by doses of $10^{15}(1), 10^{16}(2)$, and $10^{18} \mathrm{~cm}^{-2}(3)$. 
process with $E_{\mathrm{A}} \approx 18 \mathrm{~kJ} \cdot \mathrm{mol}^{-1}$, and the chemisorption kinetics is following to Eq. (2). However, it is apparent from Fig. 9 that the dependence of $\ln V_{\text {ads }}$ on $1 / T$ in the range $100-600^{\circ} \mathrm{C}$ does not correspond to Eq. (2) since the initial rate of adsorption decreases with temperature rise. The observed dependence of $\ln V_{\text {ads }}$ on $1 / T$ for irradiated $\mathrm{Cu}$ may be associated with the influence of implanted atoms and radiation defects on the adsorption process. The initial sticking coefficient may be assumed to be proportional to be concentration of defects (vacancies), that is $\sigma(O) \propto n$, where $n$, in its turn, is the quantity inversely proportional to the frequency of vacancy jumps, $n \propto 1 / v$, which is determined by the following relation [25]:

$$
v=v_{\mathrm{O}} \exp \left[-U_{m}{ }^{v} /(k T)\right],
$$

where $v_{0} \approx 10^{13} \mathrm{~s}^{-1}, U_{m}{ }^{v}$-activation energy for vacancy migration. Then,

$$
\sigma(O) \propto \exp \left[-U_{m}{ }^{v} /(k T)\right] .
$$

On the other hand, according to the second assumption of the model, the sticking coefficient should increase with a higher rate of reduction of the number of blocked centres, that is

$$
\sigma(\mathrm{O}) \propto \exp \left[-E_{\mathrm{des}} /(k T)\right] .
$$

Here, $E_{\text {des }}$ is the activation energy for the desorption of implanted

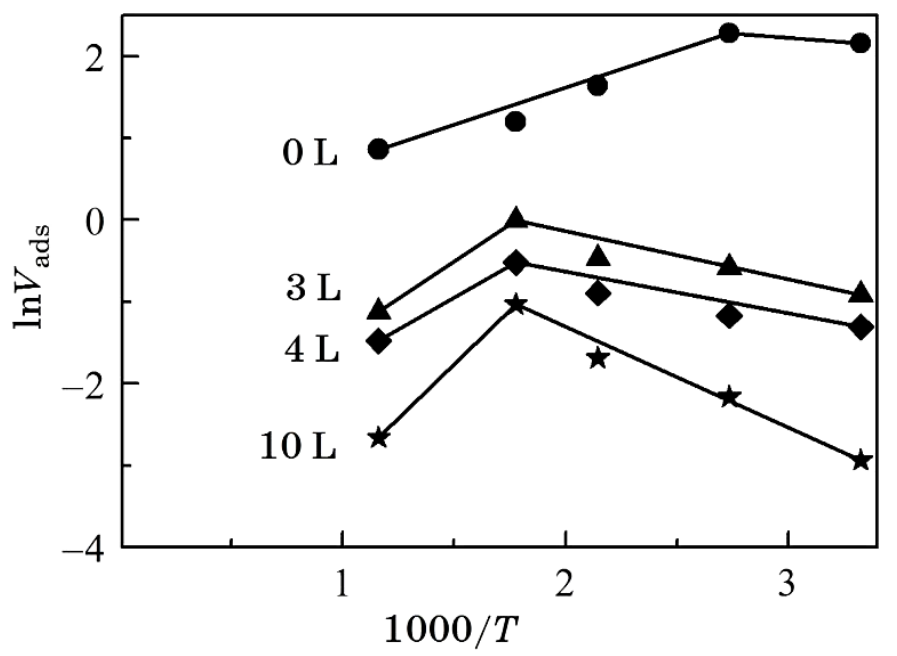

Fig. 9. Oxygen chemisorption rate $v s$. reciprocal temperature of $\mathrm{Cu}$ implanted with the dose $1 \cdot 10^{18} \mathrm{~cm}^{-2}$ of Ar ions for different oxygen exposures. 
argon atoms from the metal.

As a result, the initial rate of adsorption on the surface with defects (including both the implanted atoms and vacancies) will be defined as

$$
V_{\text {ads }} \propto \exp \left\{\left[\left(U_{m}{ }^{v}-E_{\text {des }}\right) / k-\left(E_{\mathrm{A}} / R\right)\right] / T\right\} \propto \exp \left[E^{*} /(R T)\right],
$$

where $E^{*}$ is some effective activation energy determined by the processes of blocking, migration, desorption. Since $U_{m}{ }^{v} \approx 1.7 \cdot 10^{-19} \mathrm{~J}, E_{\mathrm{des}} \approx 3.2 \cdot 10^{-20} \mathrm{~J}$, and $E_{\mathrm{A}}$ for unirradiated $\mathrm{Cu}$ equals to $18 \mathrm{~kJ} \cdot \mathrm{mol}^{-1},\left[\left(U_{m}{ }^{v}-E_{\mathrm{des}}\right) / k-E_{\mathrm{A}} / R\right]$ will be a positive quantity, and then, the dependence of $\ln V_{\text {ads }}$ on $1 / T$ in Fig. 9 will correspond to Eq. (8).

The process of annealing results in increasing mobility of vacancies, interstitials and implanted atoms, so that the initial distribution of defects is expanded and moves deeper into the bulk [26]. Partial annihilation of vacancies and interstitials is also observed. All these factors promote the reduction of the damage level in a sample and, apparently, this effect is larger the higher the annealing temperature. Therefore, the initial adsorption rate (proportional to the defect density at the surface) would be higher for samples annealed at lower temperatures, and the amount of oxygen chemisorbed at small exposures would be higher too. When the duration of $\mathrm{O}_{2}$ exposure (and annealing) is increased, the damage level of the samples, which were kept at different temperatures, becomes equal, and the process develops then as follows. When the temperature is raised, the sticking coefficient of oxygen on $\mathrm{Cu}$ increases, and accordingly, the rate of adsorption is also enhanced. The process of thermal desorption of $\mathrm{Ar}$ atoms from $\mathrm{Cu}$ at high temperatures should apparently also have a definite effect on the oxygen chemisorption kinetics, since such a process, according to presented model, unlocks the adsorption centres.

Thus, the picture varies gradually with increase in exposure, and the adsorption process follows Eq. (2) more closely. As a result, the dependence of $\ln V_{\text {ads }}$ on $1 / T$ in the temperature range $23-300^{\circ} \mathrm{C}$ and for $\mathrm{O}_{2}$ exposures of $3-10 \mathrm{~L}$ acquires the shape of the Arrhenius straight line (Fig. 9). According to Eq. (2), it is possible to determine the apparent activation energy of adsorption $E_{\mathrm{A}}^{\mathrm{L}}$ for coverage $\theta>0$ from the slope of the Arrhenius plot shown in Fig. 9 (in the range $23-300^{\circ} \mathrm{C}$ ).

Figure 10 shows the apparent activation energy for oxygen adsorption on irradiated $\mathrm{Cu}$ as a function of exposure. It may be seen that $E_{\mathrm{A}}$ increases linearly with $\mathrm{O}_{2}$ exposure. This might be explained by the fact that the adsorption centres characterized by different $E_{\mathrm{A}}(\theta)$ are gradually filled. It should be pointed out that $E_{\mathrm{A}}^{\mathrm{L}}$ values for an irradiated $\mathrm{Cu}$ surface are much smaller than for an unirradi- 


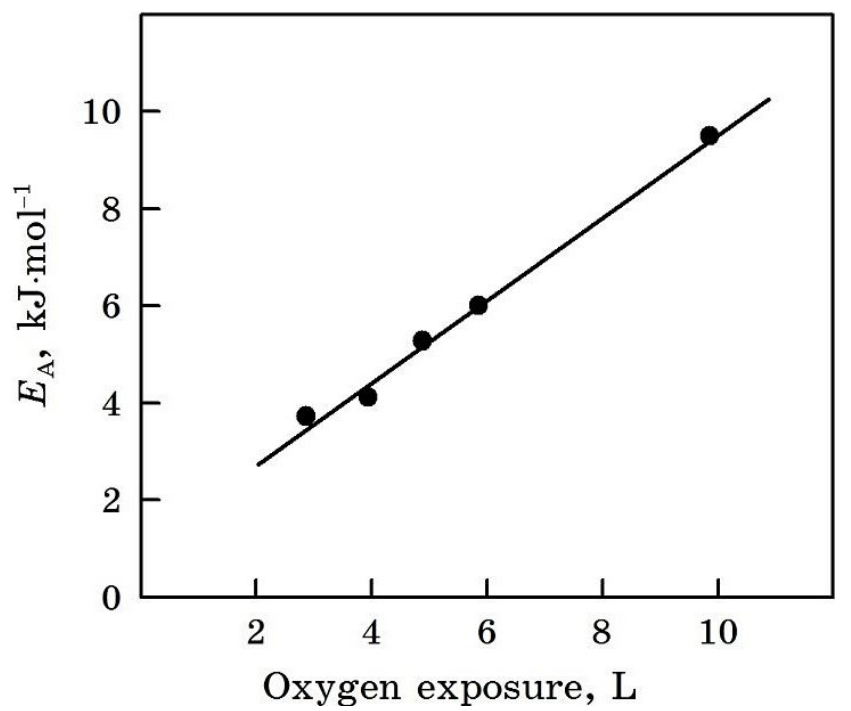

Fig. 10. Apparent activation energy of oxygen chemisorption on $\mathrm{Cu}$ irradiated with dose $1 \cdot 10^{18} \mathrm{~cm}^{-2}$ of Ar ions $v s . \mathrm{O}_{2}$ exposures.

ated one. However, values of the adsorption activation energy are likely to be due to the presence of radiation defects, which serve as the adsorption centres at small $\mathrm{O}_{2}$ exposures. It is also possible that lower values of apparent activation energy of adsorption (Fig. 10) indicate the incorporation of oxygen atoms into the metal lattice since the values of $E^{\mathrm{L}}{ }_{\mathrm{A}}$ obtained in the present work for $\mathrm{Cu}$ agreed well with the published magnitude of the activation energy for the incorporation of oxygen atoms into $\mathrm{Cu}\left(6.3-8.4 \mathrm{~kJ} \cdot \mathrm{mol}^{-1}\right)$.

\section{ALLOYS}

The first study of the oxygen chemisorption and oxidation of single-crystal alloys after preliminary ion bombardment has been performed by Chenakin [18]. AES has been used to study the oxygen chemisorption kinetics on the (110), (100), and (111) faces of $\mathrm{Fe}-36$ at. $\% \mathrm{Ni}$ before and after bombardment with $5 \mathrm{keV}$ argon ions to doses of $10^{15}-10^{17}$ ion $\cdot \mathrm{cm}^{-2}$. Clean surfaces were produced by several cycles of $600 \mathrm{eV} \mathrm{Ar}^{+}$bombardment at an ion current density of 5 $\mu \mathrm{A} \cdot \mathrm{cm}^{-2}$ and annealing at $600^{\circ} \mathrm{C}$. For the cleaned and annealed surfaces (110), (100), and (111), the $\mathrm{Ni}$ concentration estimated by AES amounted to $42,34.4$ and 40 at.\%, respectively. Both initial and implanted specimens were exposed at room temperature to high-purity oxygen at partial pressures of $1.33 \cdot 10^{-4} \mathrm{~Pa}$ (range exposures $\left.0-700 \mathrm{~L}, 1 \mathrm{~L}=1.33 \cdot 10^{-4} \mathrm{~Pa} \cdot \mathrm{s}\right)$ and $1.33 \cdot 10^{-4} \mathrm{~Pa}(700-5000 \mathrm{~L})$. 
After each exposure, the oxygen was pumped out, and Auger spectra were recorded.

It was shown that $5 \mathrm{keV} \mathrm{Ar}^{+}$ion bombardment of the alloy resulted in the preferential sputtering of $\mathrm{Ni}$, the depletion being increased with the dose. At a dose of $10^{17}$ ion $\cdot \mathrm{cm}^{-2}$, the Ni concentration on the (110), (100), and (111) faces was 21.8, 21.7, and 17.4 at. $\%$, respectively. The preliminary bombardment resulted in enhancement of the alloy oxidation as compared with the unimplanted sample. The initial chemisorption rate $V_{\text {ads }}$ and the amount of oxygen chemisorbed at $5000 \mathrm{~L}$ were observed to increase with the growth in ion dose (cf. Fig. 11, $a$ and $b$ ). The $V_{\text {ads }}$ increased particularly for the (100) and (111) faces, and its values became close for all faces. As a result, after an ion dose of $10^{15}$ ion $\cdot \mathrm{cm}^{-2}$, the $\mathrm{O}_{2}$ uptake at $20^{\circ} \mathrm{C}$ was almost isotropic (Fig. 11, a). Bombardment with doses of $10^{16}$ and $10^{17}$ ion. $\mathrm{cm}^{-2}$ did not alter appreciably the oxidation kinetics character (Fig. 11, b); it remained virtually orientation-independent, although for all the doses used the (100) surface tended somewhat to retain its adsorption characteristics, namely to chemisorbed at large exposures more oxygen than other faces.

The orientation dependence of surface depletion with $\mathrm{Ni}$ after a dose of $10^{17}$ ion $\mathrm{cm}^{-2}$ seems to be for various crystal faces, which is
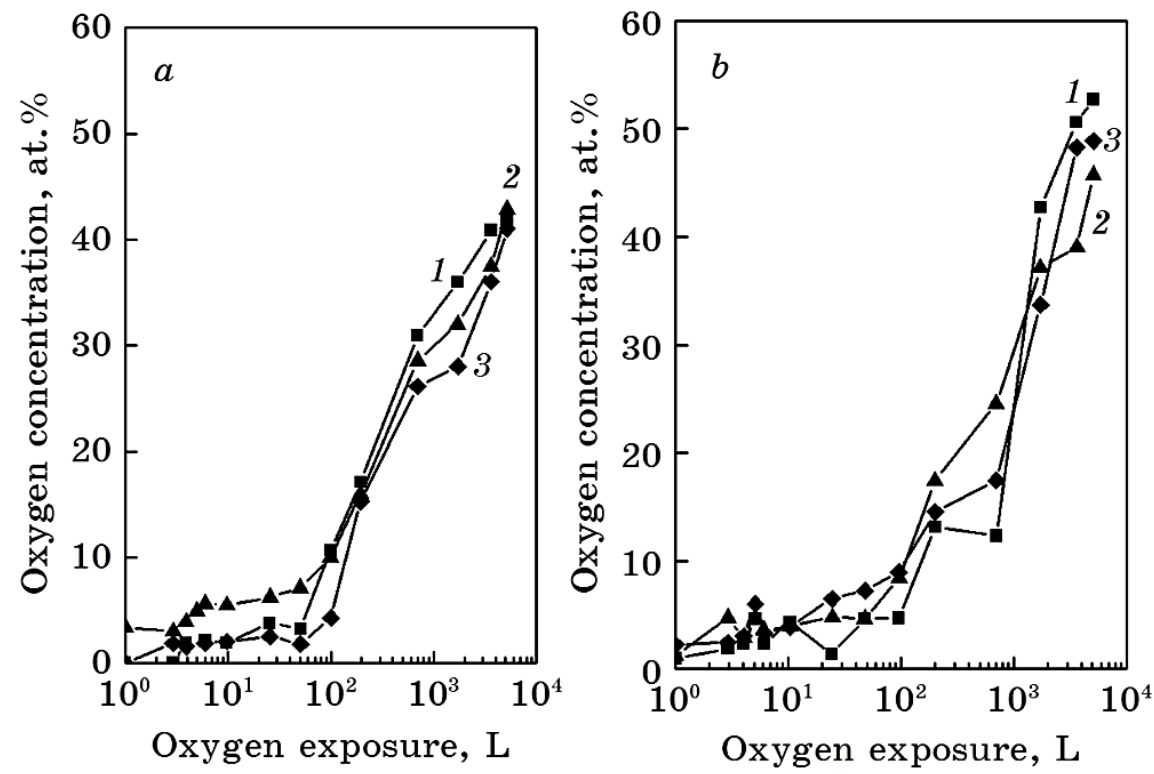

Fig. 11. Oxygen surface concentration as a function of $\mathrm{O}_{2}$ exposure at room temperature for the faces: (100)-1, (110)-2, (111)-3 of $\mathrm{Fe}-36$ at. $\% \mathrm{Ni}$ crystal after preliminary bombardment with $5 \mathrm{keV} \mathrm{Ar}^{+}$to doses of $10^{15}(a)$ and $10^{17} \mathrm{~cm}^{-2}(b)$. 
known to be the largest for the most close-packed faces and in accordance with the capability of primary ions for channelling along close-packed directions, it decreases for f.c.c. crystals in the sequence as follows: $S(111)>S(100)>S(110)$. Accordingly, the $\mathrm{Ni}$ surface concentration for the irradiated f.c.c.-Fe-Ni crystal will grow in the same face sequence.

Ion bombardment of $\mathrm{Fe}-\mathrm{Ni}$ crystal produces defects, disorders crystal structure, and alters the surface composition. In spite of the noticeable increase in carbon concentration on the high-dose irradiated surfaces as compared with unirradiated ones, $V_{\text {ads }}$ rises substantially $(\approx 2$ times). Evidently, the surface defects facilitate this enhancement of $V_{\text {ads }}$, and the increase of $V_{\text {ads }}$ on a given face for larger ion doses is ensured by the growth of radiation damage density. At a given dose, the damage level will be higher for more closepacked crystal surfaces, and this will cause the $V_{\text {ads }}$ for various faces to be equalized. With a drought of ion dose, this tendency seems to be maintained, so, the oxidation kinetics manifests almost isotropic character in the wide dose range of $10^{15}-10^{17} \mathrm{ion} \cdot \mathrm{cm}^{-2}$. The differences in $\mathrm{Fe}$ concentration level after irradiation at a dose of $10^{17}$ ion $\cdot \mathrm{cm}^{-2}$ do not affect the kinetics appreciably, rather the contrary, some stability of the adsorption characteristics for $\mathrm{Fe}-$ $\mathrm{Ni}(100)$ may be connected with the role of $\mathrm{Ni}$, the selective sputtering of which was the least for the (100) face.

Annealing of the irradiated $\mathrm{Fe}-\mathrm{Ni}$ crystal at $300^{\circ} \mathrm{C}$ for $30 \mathrm{~min}$ eliminates the defects and largely restores the ordered surface structure. The anisotropy, $V_{\text {ads }}(110)>V_{\text {ads }}(111)>V_{\text {ads }}(100)$, is restored again, although to a lesser extent. The highest $V^{0}$ ads occurs for the (110) face, where the $\mathrm{Ni}$ concentration is largest. This indicates that, for irradiated crystals, structural effects predominate over

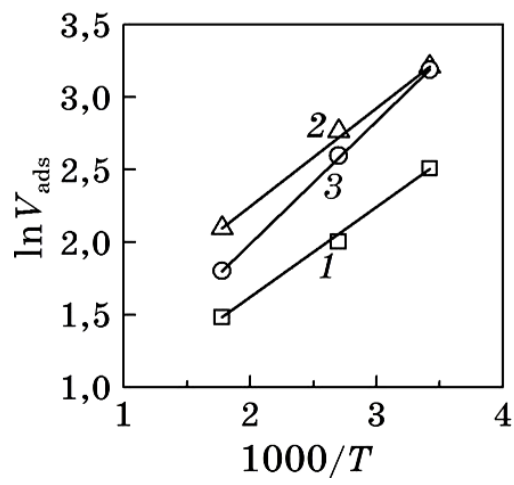

Fig. 12. Initial oxygen chemisorption rate as a function of reciprocal temperature for the faces: (100) - 1, (110) - 2, (111) -3 of $\mathrm{Fe}-36$ at. \% Ni crystal irradiated with $5 \mathrm{keV} \mathrm{Ar}^{+}$to a dose of $10^{17} \mathrm{~cm}^{-2}$. 
compositional ones too. Figure 12 shows $V_{\text {ads }}$ derived from the curves of $C_{\mathrm{O}}=f(L)$ for the $\mathrm{Fe}-\mathrm{Ni}$ faces irradiated at a dose of $10^{17}$ ion. $\mathrm{cm}^{-2}$ and exposed in $\mathrm{O}_{2}$ at $20-300^{\circ} \mathrm{C}$ as a function of $1 / T$. One can see that the effective activation energy, $E_{0}$, only slightly depends on the surface orientation and varies in the range from -5 to $-8 \mathrm{~kJ} \cdot \mathrm{mol}^{-1}$. The negative values, if $E_{\mathrm{O}}$ indicating non-activated adsorption, are the consequence of the combined action of such processes as chemisorption, defect annealing, argon desorption and segregation, and correspond to the conclusions from a model of oxygen chemisorption on an implanted surface.

\section{CONCLUSION}

Closer examination of the influence of inert gas ion bombardment with incident ion energies of order of $1 \mathrm{keV}$ on the surface chemical activity has been performed by the examples of gas-surface interaction in vacuum conditions, in particular, of the kinetics of oxygen interaction with surface of $\mathrm{Cu}, \mathrm{Ni}, \mathrm{Fe}$ and $\mathrm{Fe}-\mathrm{Ni}$ alloy using variety of techniques. It was reported that gas-surface interactions and surface reactivity is strongly controlled by the optimal relation between the energy and the density of the primary ion current as well as the sputtering rate of the natural oxide and pure metal. The increase in the oxidation rate at high doses may be as results a large number of defects and the relief created on the metal surfaces. Point defects (such as vacancies or dislocation emergence points) and clusters of point defects created at the surface by ion bombardment serve adsorption centres and thus enhance the adsorption rate. Implanted Ar ions block up the adsorption centres by reducing the chemisorption energy on atoms nearest to defects so that the adsorption rate becomes lower. The competitive effect of these two factors on the adsorption process should determine the kinetic character of interaction between oxygen and an irradiated metal.

\section{REFERENCES}

1. A. J. R. van den Boogaard, E. Zoethout, I. A. Makhotkin, E. Louis, and F. Bijkerk, J. Appl. Phys., 112: 123502 (2012).

2. S. Zuccon, E. Napolitani, E. Tessarolo, P. Zuppella, A. J. Corso, F. Gerlin, M. Nardello, and M. G. Pelizzo, Opt. Mater. Express, 5: 176 (2014).

3. X. Li, K.-W. Lin, H.-T. Liang, H.-F. Hsu, N. G. Galkin, Y. Wroczynskyj, J. Van Lierop, and P. W. T. Pong, Nucl. Instrum. Methods Phys. Res. Sect. B, 365: 196 (2015).

4. L. Repetto, R. Lo Savio, B. Šetina Batic, G. Firpo, E. Angeli, and U. Valbusa, Nucl. Instrum. Methods Phys. Res. Sect. B, 354: 28 (2015).

5. S. Ninomiya, K. Ichiki, H. Yamada, Y. Nakata, T. Seki, T. Aokic, and 
J. Matsuo, Surf. Interface Anal., 43: 95 (2011).

6. Y. Fujiwara and N. Saito, Appl. Phys. Express, 8: 076601 (2015).

7. M. Sugiyama and G. Sigesato, J. Electron Microscopy, 53: 527 (2004).

8. T. A. Bakhsh, A. Sadr, and J. Tagami, J.Adhes. Sci. Technol., 29: 232 (2015).

9. R. K. Sherburne and H. E. Farnsworth, J. Chem. Phys., 19: 387 (1951).

10. V. Ashworth, W. A. Grant, R. P. M. Procter, and T. C. Wellington, Corrosion Science, 16: 393 (1976).

11. V. T. Cherepin, M. A. Vasil'ev, and Yu. N. Ivashchenko, Doklady AN SSSR, 210: 821 (1973) (in Russian).

12. Yu. M. Khirnyi and A. P. Solodovnikov, Doklady AN SSSR, 214: 82 (1974) (in Russian).

13. V. T. Cherepin, A. A. Kosyachkov, and M. A. Vasiliev, Surf. Sci., 58: 609 (1976).

14. R. Miranda, J.M. Rojo, and M. Salmeron, Solid State Comm., 35: 83 (1980).

15. L. Gonzalez, R. Miranda, and S. Ferrer, Solid State Comm., 44: 1461 (1982).

16. R. Miranda and J. M. Rojo, Vacuum, 34: 1069 (1984).

17. S. P. Chenakin, Vacuum, 36: 635 (1986).

18. S. P. Chenakin, Appl. Surface Sci., 84: 91 (1995).

19. V. E. Yurasova, V. T. Cherepin, and Yu. A. Ryzhov, Journal of Surface Investigation. X-Ray, Synchrotron and Neutron Techniques, 5: 465 (2011).

20. H. Albers, W. J. J. Van der Wal, and G. A. Bootsma, Surface Sci., 68: (1977).

21. R. Miranda, J. M. Rojo, and M. Salmeror, J.Vac. Sci. Technol., 18: 596 (1981).

22. G. E. Rhead, Surface Sci., 68: 20 (1977).

23. J. C. Tsai and J. M. Morabito, Surface Sci., 44: 247 (1974).

24. H. E. Schiott, Rad. Effects, 6: 107 (1970).

25. M. Slater, G. Garterand, and W. A. Grant, Nucl. Instrum. Meth., 209-210: 1023 (1983). 